\title{
The echocardiographic and radiological profile of Clinically diagnosed congenital heart disease in children
}

\author{
Bhaskar S. ${ }^{1}$, Sneha P. ${ }^{2 *}$, Babu R M. ${ }^{3}$, Chithambaram. ${ }^{4}$ \\ DOI: https://doi.org/10.17511/ijpr.2021.i04.04 \\ 1 Sandeep Bhaskar, Associate Professor, Department of Paediatrics, Vydehi Institute of Medical Sciences \& Research Centre, Bangalore, \\ Karnataka, India. \\ 2* Sneha P, Senior Resident, Department of Paediatrics, Vydehi Institute of Medical Sciences \& Research Centre, Bangalore, Karnataka, \\ India. \\ 3 Manjunath Babu R, Professor, Department of Paediatrics, Akash Institute of Medical Sciences, Devanahalli, Karnataka, India. \\ ${ }^{4}$ Chithambaram, Professor, Department of Paediatrics, PES Institute of Medical Sciences\& Research, Kuppam, Andhra Pradesh, India.
}

Introduction: Congenital heart disease (CHD) if diagnosed clinically early and confirmed by Chest $X$-ray and ECHO, can be appropriately managed. Objectives: To observe the clinical profile of CHD in clinically diagnosed $\mathrm{CHD}$ in children To correlate the clinical profile with radiological and echocardiographic findings in the study group. Methods: It's a cross-sectional study. The duration was 18 months. All children in the age group of 1 month to $18 y e a r s$ of age with history \& clinical findings suggestive of CHDs were taken, assessed, subjected to Chest X-ray \& 2 DECHO \& were correlate. Results: Total no. of cases admitted during the study period was 5423, 624 had CHD among which 50 fulfilling the criteria were taken. Clinically CCHD was in 34\%, ACHD in 66\%. Clinical correlation with X-ray was $83 \%$ and with ECHO was $87 \%$. Conclusion: ACHD is more common, Chest $x$-ray findings correlated closely. ECHO correlation with the clinical diagnosis was very accurate especially in isolated lesions and some cases were identified which had been missed clinically. Hence Clinical Diagnosis with X-ray and ECHO helps in increased identification \& earlier intervention of CHDs.

Keywords: Congenital heart disease, Acyanotic Congenital heart disease, Cyanotic CHD, Chest XRay, ECHO

Corresponding Author

Sneha P, Senior Resident, Department of Paediatrics, Vydehi Institute of Medical Sciences \& Research Centre, Bangalore, Karnataka, India.

Email: drsnehapilanku2021@gmail.com
How to Cite this Article

To Browse

Bhaskar S, Sneha P, Manjunath Babu R, Chithambaram. The echocardiographic and radiological profile of Clinically diagnosed congenital heart disease in children. Pediatric Rev Int J Pediatr Res. 2021;8(4):189-195.

Available From

https://pediatrics.medresearch.in/index.php/ijpr/arti

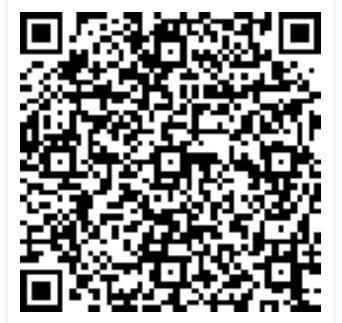
cle/view/692
Manuscript Received 2021-06-30

Conflict of Interest No

Review Round 1
2021-07-10
Funding
Nil

Review Round 2 2021-07-20

Ethical Approval Yes

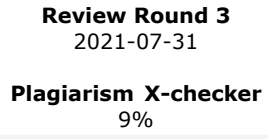

Accepted 2021-08-19

Note

(c) 2021 by Sandeep Bhaskar, Sneha P, Manjunath Babu R, Chithambaram and Published by Siddharth Health Research and Social Welfare Society. This is an Open Access article licensed under a Creative Commons Attribution 4.0 International License https://creativecommons.org/licenses/by/4.0/ unported [CC BY 4.0]. 


\section{Introduction}

Congenital heart disease (CHD) comprises one of the major diseases in the pediatric age group and is one of the leading causes of death in children with congenital malformations. CHD by definition is the structural or functional heart disease present at the time of birth, even if it is detected later on [1]. The incidence of $\mathrm{CHD}$ in the normal population is approximately $0.5-0.8 \%$ of live-born children, with a higher percentage in those aborted spontaneously or stillborn.

In our country, the majority of childbirths still takes place at home and routine neonatal screening is not common, so it is difficult to calculate the true birth prevalence of CHD [2]. Echocardiography done for the suspected babies has increased the detection of various CHD [3]. Pediatric cardiac care in India is still in its infancy. There are very few specialized pediatric cardiology training programs, those that are, are concentrated in certain regions of India and are often imparted through combined adult and pediatric programs.

Training programs exclusively dedicated to pediatric cardiology and pediatric cardiac surgery need to be established in centres with good standards of pediatric cardiac care [4]. With newer diagnostic modalities including echocardiography, it is now considered as near confirmatory in diagnosing most congenital heart lesions. $X$ ray chest and ECG are complementary to echocardiography. Chest $X$-ray is usually the first radiography performed for a newborn. This test is easily accessible and yet a basic screening method. Digital radiography has improved this method. Most studies using colorDoppler echocardiography have reported higher incidence, which means that this method had facilitated the detection of asymptomatic lesions to a great extent [5].

Echocardiography represents the non-invasive tool most commonly used in pediatric cardiology. Indeed, it enables the definition of both the morphological and functional findings in congenital heart disease (CHD), as completely as possible in almost all cases [6]. With limited resources in developing countries like India clinical acumen still forms the backbone of diagnosis and treatment, later to be confirmed by echocardiography and to deliver the appropriate management at the right time. It would also allow the physician to identify relatively unnoticed syndromes and act swiftly [7].

\section{Objectives}

To observe the clinical profile of CHD in clinically diagnosed $\mathrm{CHD}$ in children.

To correlate the clinical profile with radiological and echocardiographic findings.

\section{Material \& Method}

Setting: At the Paediatric ward of a Tertiary Care Hospital \& Medical College.

Duration \& Type of Study: One \& a half years, cross-sectional study.

Sampling Methods: Simple Random Technique.

Sample size calculation: Sample of 50 cases between the age group of 1 month to 18 years attending the hospital during the study period was selected by Simple Random Technique.

Inclusion criteria: Children from 1month to 18 years of age with clinically suspected cases of CHD

\section{Exclusion criteria:}

-Acquired heart disease.

-Established cases of Congenital heart disease

Data Collection Procedure: All children in the age group of 1 month to 18 years of age with complaints of recurrent chest infection, respiratory distress, cyanotic spells, squatting episodes, poor feeding, failure to thrive and other relevant history and examination findings suggestive of CHD were included in this study. Informed consent was taken from parents or caregivers.

The study group was first assessed clinically according to a performed proforma after getting the written consent. They underwent Chest X-ray and Electrocardiogram. The final diagnosis was confirmed by Echocardiography. Clinical diagnosis of the suspected CHD was then correlated with X-ray findings and Echocardiography.

Any Scoring System: used- Nil.

\section{Surgical Procedure if any: Nil}

Ethical Consideration: Taken. Approved by the Ethical Committee of the Tertiary Care Medical Teaching Hospital.

Statistical analysis: Sample of 50 cases attending the hospital during the study period was selected by Simple Random Technique. Data were entered into a 
Microsoft Excel datasheet and was analyzed using SPSS 22 version software. Categorical data was represented in the form of Frequencies and proportions. The Chi-square test was used as a test of significance for qualitative data. Continuous data were represented as mean and SD. P-value (Probability that the result is true) of $<0.05$ was considered as statistically significant after assuming all the rules of statistical tests.

\section{Results}

Table 1: Hospital incidence of CHD during the study period

\begin{tabular}{|l|l|}
\hline \multicolumn{1}{|c|}{ Total admission during the study period } & $\mathbf{5 4 2 3}$ \\
\hline Total CHDS during the study period & 124 \\
\hline CHDs was taken into the study during the study period & 50 \\
\hline Percentage of CHD in the study & $0.92 \%$ \\
\hline
\end{tabular}

Table - 1Shows that out of 5423 patients admitted 124 patients were found to have CHDs and the hospital incidence of CHD is $2.28 \%$.

Table 2: Distribution of CHD by mode of presentation clinically

\begin{tabular}{|l|l|l|}
\hline \multicolumn{1}{|c|}{ Mode of presentation } & No cases of CHD & Percentage \\
\hline Breathlessness & 32 & 64 \\
\hline Chest pain & 6 & 12 \\
\hline Cough & 39 & 78 \\
\hline Cyanosis & 13 & 26 \\
\hline Fever & 20 & 40 \\
\hline Chest pain & 18 & 36 \\
\hline Feeding difficulties & 20 & 40 \\
\hline FTT PEM Malnutrition & 27 & 54 \\
\hline Palpitation & 5 & 10 \\
\hline Fatigue & 4 & 8 \\
\hline Suck rest suck cycle & 4 & 8 \\
\hline Forehead sweating & 15 & 30 \\
\hline
\end{tabular}

Table 2 depicts that cough and breathlessness were major symptoms.

Table 3: Distribution of CHD cases by Clinical Diagnosis

\begin{tabular}{|l|l|l|}
\hline \multicolumn{1}{|c|}{ Type of CHD } & \multicolumn{1}{c|}{ No of cases } & \multicolumn{1}{c|}{ Percentage } \\
\hline CCHD & 16 & 32 \\
\hline ACHD & 34 & 68 \\
\hline Total & 50 & 100 \\
\hline
\end{tabular}

Acyanotic CHD comprises $68 \%$ of total cases.

Table 4: Distribution of CHD cases by Chest Xray findings

\begin{tabular}{|l|l|l|}
\hline \multicolumn{1}{|c|}{ Chest $x$-ray findings } & No of cases & Percent \\
\hline Cardiomegaly & 35 & 70 \\
\hline Increased pulmonary vascular marking & 20 & 40 \\
\hline Decreased pulmonary vascular markings & 16 & 32 \\
\hline RVH/LVH & 24 & 48 \\
\hline Pneumonia & 8 & 16 \\
\hline
\end{tabular}

As per the table Cardiomegaly and hypertrophy were major findings.

Figure-1: Distribution of CHD cases by Chest Xray findings

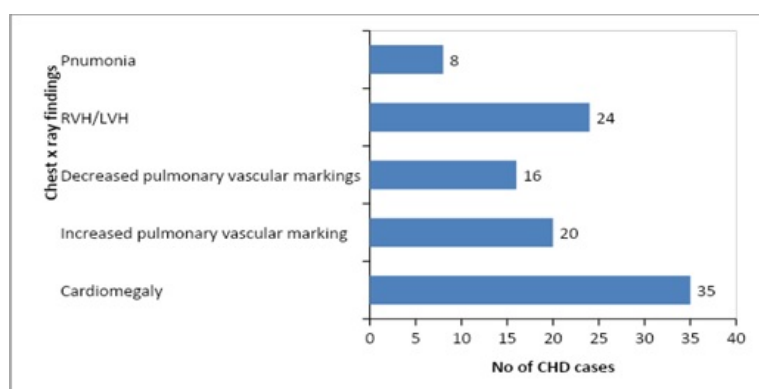

Table 5: Correlation of Clinical features with Chest X-ray

\begin{tabular}{|l|l|l|}
\hline \multicolumn{1}{|c|}{ Correlation present or absent } & No of CHD cases & Percentage \\
\hline Correlating & 40 & 80 \\
\hline Not Correlating & 10 & 20 \\
\hline Total & 50 & 100 \\
\hline
\end{tabular}

Figure 2: Correlation of Clinical features with Chest x-ray

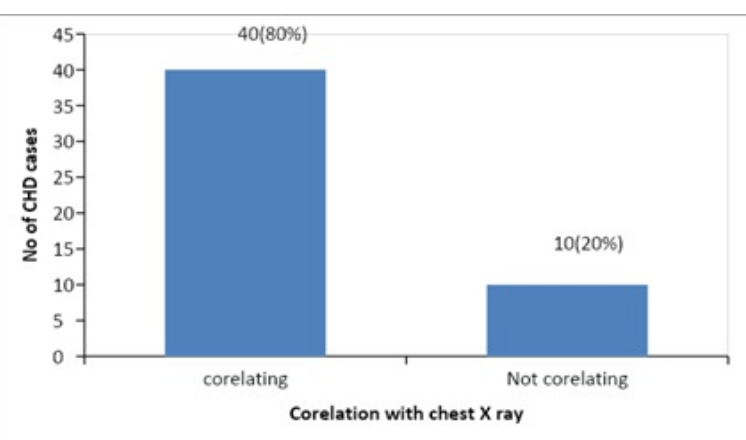

Table 6: Distribution of CHD cases by ECHO findings

\begin{tabular}{|l|l|l|}
\hline \multicolumn{1}{|c|}{ Type of CHD } & No of cases & \multicolumn{1}{c|}{ Percentage } \\
\hline CCHD & 20 & 40 \\
\hline ACHD & 30 & 60 \\
\hline Total & 50 & 100 \\
\hline
\end{tabular}

Echo also suggested ACHD in $60 \%$ of cases.

Table 7: Correlation of Clinical diagnosis of total CHD with ECHO findings 


\begin{tabular}{|l|l|l|}
\hline \multicolumn{1}{|c|}{ Correlation with ECHO } & No of CHD cases & Percentage \\
\hline Not Correlating & 10 & 20 \\
\hline Correlating & 40 & 80 \\
\hline Total & 50 & 100 \\
\hline
\end{tabular}

Figure 3: Correlation of Clinical Diagnosis of total CHD cases with Echo findings

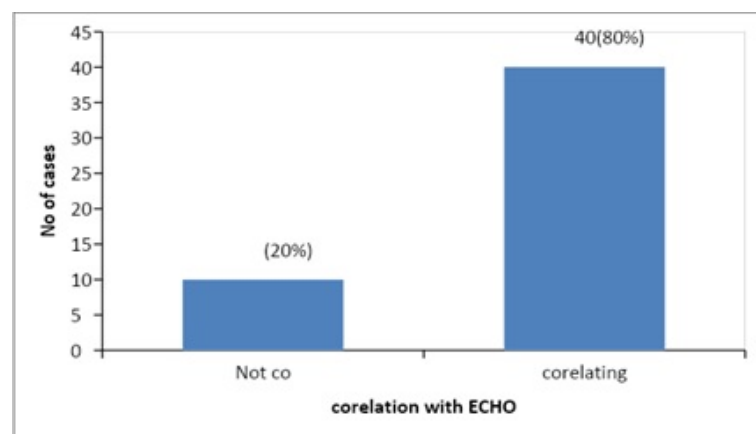

\section{Discussion}

The term congenital is derived from the Latin word ('con' means together and'genitus' meaning born) referring to 'present at birth'. Congenital heart disease (CHD) is defined as an abnormality in 'cardiocirculatory' structure or function that is present since birth, even though it may be discovered later [8].

Thomas Bevill Peacock was a physician who practised in the 1800 s at St Thomas'Hospital in London. He was the first to classify CHD into 4 categories: misplacements of the heart, pericardial abnormalities, cardiac malformations, and irregularities of the primary vessels. Peacock wrote about the causes of CHD, attributing most forms to abnormalities in embryonic development, particularly growth arrest [9].

The estimated birth prevalence of CHD is $8 / 1000$ live births with a significant geographical difference. A recent systemic review reported the highest prevalence (9.3/1000 live births) in Asia due to the high birth rate and consanguineous marriages and the lowest prevalence in Africa (8.2/1000 live births).

In India, over 180,000 children are born with CHD every year with state-wise variation and contribute to $10 \%$ of the present infant mortality. Nearly onethird of the CHD is critical, requiring intervention in the 1st year of life. Most of the CHD is thought to be multifactorial and result from a combination of genetic and environmental insult. [10] Fetal echocardiography can make a more accurate diagnosis of $\mathrm{CHD}$ even before birth.
With currently available treatment modalities over $75 \%$ of infants born with critical heart disease can survive beyond the first year of life and many can lead a normal life thereafter [11]. Cardiogenesis begins on the 18th day of life with the formation of the carcinogenic crescent of the precardiac mesoderm and normally is completed by the 45th day of life with the formation of the membranous part of the ventricular septum. Cardiovascular maturation continues well after birth. [12]

The main differences between the fetal and postnatal circulation are: a) Presence of placental circulation, which provides a gas exchange for the fetus

01 . The absence of gas exchange in the collapsed lungs results in very little flow of blood to the lungs and thus little pulmonary venous return to the left atrium

02. Presence of ductus venosus, joining the portal vein with the inferior vena cava, providing a low resistance bypass for umbilical venous blood to reach the inferior vena

03. Widely open foramen ovale to enable oxygenated blood (through umbilical veins) to reach the left atrium and ventricle for distribution to the coronaries and the brain; and lastly

04. Wide open ductus arteriosus to allow right ventricular blood to reach the descending aorta, since lungs are non-functioning.[13].

Circulatory adjustments at birth: The sudden expansion of lungs with the first few breaths causes a fall in pulmonary vascular resistance and an increased flow into the pulmonary trunk and arteries. The pulmonary artery pressure falls due to the lowering of pulmonary vascular resistance. The pressure relations between the aorta and pulmonary trunk are reversed so that the flow through the ductus is reversed. Instead of blood flowing from the pulmonary artery to the aorta, the direction of flow through the ductus, is from the aorta to the pulmonary trunk.[14].

Frequency of Lesions: The relative frequency of the most common lesions varies but nine common lesions form $80 \%$ of CHD. These are VSD (36\%), ASD (5\%), patent arterial duct (9\%), atrioventricular septal defect (AVSD) (4\%), pulmonary stenosis (PS) (9\%), AS (5\%), coarctation of aorta $(5 \%)$, transposition of great arteries ( $4 \%$ ), and TOF (4\%). The other $20 \%$ of CHD consists of many rare or complex lesions $[15]$. 
Common clinical features: Breathlessness, chest retractions, FTT, Feeding difficulty, cyanosis were the common clinical presentations in congenital heart disease. CHD should be suspected in all cases of recurrent chest infections and failure to thrive. A high index of suspicion, a detailed history, physical examination, chest x-ray, electrocardiogram along Echocardiography helps us to diagnose most of the congenital heart disease. With limited resources, clinical acumen forms the backbone for diagnosis for CHD. Early detection and intervention reduce the morbidity and mortality of CHD [16]. In our study five thousand four hundred and twenty-three (5423) children ( $<18$ years ) were admitted during the study period of whom 124 were found to have CHD. Among these fifty cases of CHD were selected by Simple Random Technique, satisfying the inclusion criteria.

In the present study, the hospital incidence of CHD is $2.28 \%$ of all admissions. This is comparable with other studies by Rakshit Reddy et al where incidence was found to be $1.85 \%$. [8] In a study done by Shymsundar incidence was $2.1 \%$ [17]. and $2.5 \%$ in a study done by A.Saxena et al [18]. In our study in clinical features, breathlessness was the commonest and it was in $64 \%$ followed by cough in $78 \%$ and fever in $40 \%$ of cases whereas in a study done by Karthigaet al the incidence of breathlessness, cough and fever were present in 72 $\%, 70 \%$ and $60 \%$ repectively[2] and in a study done by Rakshith et al it was $68 \%, 64 \%$ and $58 \%$ respectively[8]. In our study the distribution of $\mathrm{CHD}$ cases by clinical diagnosis was $68 \%$ for ACHD and $32 \%$ for CCHD cases. In a study done by Chandra SekharKondapalli it was $85 \%$ for ACHD and $15 \%$ for CCHD [3].

In a study done by Rakshit Reddy et al it was $82 \%$ for ACHD and $18 \%$ for CCHD [8]. In our study as per the chest $x$-ray findings following were there Cardiomegaly, Increased pulmonary vascular markings (Pulmonary plethora), Decreased Pulmonary vascular markings (Pulmonary oligemia), RVH/LVH, Pneumonia in $70 \%, 40 \%, 32 \% 48 \%$ and $16 \%$ respectively. In a study done by Chandra SekharKondapalli incidence was $78 \%, 47 \%, 20 \%$ and $10 \%$ respectively [3]. whereas in a study done by Laya B et al it was $65 \%, 25 \%, 10 \%$ and $30 \%$ respectively [19]. In our study the correlation of clinical profile with chest $x$-ray was $80 \%$. In a study done by Chandra ShekarKondapalli it was $80 \%$ [3] and in a study done by Akbar et al 3 it was 63\%[4] and in a study done by Laya et al it was $71 \%$ [19].
In all these studies clinical diagnosis is strongly correlated and supported by chest $x$-ray findings. In our study the clinical diagnosis correlating with echo was $80 \%$. In a study done by Mir $\mathrm{D}$ et al the incidence was found to be the same $69 \%$ fully correlating and $19 \%$ partially correlating [1] and in a study done by Rakshith Reddy et al full correlation was seen in $73 \%$ and partial correlation in $14 \%$ [8]. In a study by Swenson et al and Klewer et al the clinic echo correlations were $82 \%$ and $81 \%$ respectively [20] [21]. In all these studies it is proven that clinical diagnosis of $\mathrm{CHDs}$ are strongly correlating with ECHO diagnosis and also ECHO helps in identifying rare and difficult lesions missed clinically.

\section{Conclusion}

ACHD is far more common than CCHD and overall VSD is the most common CHD. Among ACHDs, VSD was the most common and among CCHD, TOF is the most common. The most common presenting symptoms in CHD was cough and breathlessness. Chest X-ray is important corroborative evidence in the diagnosis of CHD and was abnormal in $80 \%$ of cases with the presence of Cardiomegaly in $70 \%$ of all cases. Properly carried out the clinical examination, Chest X-ray and $\mathrm{ECHO}$ evaluation are important tools in arriving at a near accurate diagnosis in CHD, however before undertaking surgical intervention echocardiographic confirmation of the diagnosis is required.

\section{Contribution by different authors}

Dr. Sneha conceptualized and designed the study, interpreted data, revised the manuscript and approved the final version to be published. She will act as the guarantor of the study. Dr. Sandeep acquired the data, drafted the article and helped in the final approval of the manuscript. Dr. Manjunath Babu analyzed the data, revised contents and helped in final approval.

\section{What this study adds to the existing Knowledge}

As in countries like India with limited resources clinical acumen forms the backbone for diagnosis for CHD. But clinical diagnosis should be confirmed with 2D Echocardiography which is a gold standard investigation for diagnosis. 
This study also suggests that once a clinical diagnosis of $\mathrm{CHD}$ has been made, Chest X-ray \& $\mathrm{ECHO}$ with their strong correlation with the clinical findings help in arriving at an accurate diagnosis especially before undertaking surgical interventions. Also with the help of ECHO some missed out cases could also be identified.

\section{Reference}

01. Mir D. Time to diagnosis, clinical features of patients admitted with congenital heart diseases in a teaching hospital. Journal Of Medical Science And Clinical Research. 2019;7(4). doi: 10.18535/ jmscr/v7i4.108 [Crossref][PubMed][Google Scholar]

02. Karthiga S, Shweta Pathak, and Monica Lazarus. Clinical and anthropometric profile of congenital heart disease in children admitted in pediatric ward. International Journal of Scientific Study. 5;5 (2017)112-7. [Crossref][PubMed][Google Scholar]

03. Kondapalli C, Gondi K, Madana S. Evaluation of congenital heart disease clinically and by echocardiography in children of age group 0-12 years. International Journal Of Contemporary Pediatrics. 2019;6(2)507. doi: 10.18203/23493291.ijcp20185516 [Crossref][PubMed][Google Scholar]

04. Molaie A, Abdinia B, Zakeri R, Talei A. Diagnostic value of chest radiography in pediatric cardiovascular diseases- A retrospective study in Tabriz, Northwest of Iran. International Journal of Pediatrics. 32;1(2015)9-13. [Crossref][PubMed] [Google Scholar]

05. Sharmin L S, Haque M A, Bari M I, Ali M A. Pattern and clinical profile of congenital heart disease in a teaching hospital. TAJ- Journal of teachers association. 21;1(2008)58-62. [Crossref] [PubMed][Google Scholar]

06. Pacileo G, Di Salvo G, Limongelli G, Miele T, Calabrò R. Echocardiography in congenital heart disease- usefulness, limits and new techniques. J Cardiovasc Med (Hagerstown). 2007 Jan;8(1)17-22. doi: $\quad$ 10.2459/01.JCM.0000247430.36581.c2 [Crossref][PubMed][Google Scholar]

07. Eskedal L, Hagemo P, Eskild A, Aamodt G, Seiler K, Thaulow E. A population-based study of extracardiac anomalies in children with congenital cardiac malformations. Cardiology In The Young. 2004;14(6)600-607. doi: 10.1017/s104795 1104006043 [Crossref][PubMed][Google Scholar]
08. Reddy Rakshit, Amar Taksande. "Clinical Profile of Congenital Heart Disease in a Tertiary Care Hospital in Central India". Journal of Datta Meghe Institute of Medical Sciences University. 11;81-86. [Crossref][PubMed][Google Scholar]

09. Gelb BD. History of Our Understanding of the Causes of Congenital Heart Disease. Circ Cardiovasc Genet. 2015 Jun;8(3)529-36. doi: 10.1161/CIRCGENETICS.115.001058 [Crossref] [PubMed][Google Scholar]

10. Meshram, Rajkumar Motiram, and Vishal Shankarrao Gajimwar. "Prevalence, profile, and pattern of congenital heart disease in Central IndiaA prospective, observational study". Nigerian Journal of Cardiology. 15;1(2018)45. [Crossref] [PubMed][Google Scholar]

11. el Hag AI. Pattern of congenital heart disease in Sudanese children. East Afr Med J. 1994 Sep;71(9)580-6. [Crossref][PubMed][Google Scholar]

12. Schoenwolf G C, Bleyl S B, Brauer P R, FrancisWest $\mathrm{P}$ H. Larsen's human embryology E-book. Elsevier. (2020). [Crossref][PubMed][Google Scholar]

13. Morton SU, Brodsky D. Fetal Physiology and the Transition to Extrauterine Life. Clin Perinatol. 2016 Sep;43(3)395-407. doi: 10.1016/j.clp.2016.04.001 [Crossref][PubMed][Google Scholar]

14. Kiserud T, Acharya G. The fetal circulation. Prenat Diagn. 2004 Dec 30;24(13)1049-59. doi: 10.1002/pd.1062 [Crossref][PubMed][Google Scholar]

15. Karthiga S, Shweta Pathak, and Monica Lazarus. "Clinical and anthropometric profile of congenital heart disease in children admitted in pediatric ward". International Journal of Scientific Study. 5;5(2017)112-117. [Crossref][PubMed][Google Scholar]

16. S A. Study of Signs, Symptoms and Investigations of Congenital Heart Disease in $A$ Teaching Hospital. Journal Of Medical Science And Clinical Research. 2017;05(05);21801-21805. doi: 10.18535/jmscr/v5i5.94 [Crossref][PubMed][Google Scholar]

17. Shyamsunder D. Clinical Profile of Congenital Heart Disease in RIMS Hospital. Journal Of Medical Science And Clinical Research. 2018;6(12). doi: 10.18535/jmscr/v6i12.182 [Crossref][PubMed] [Google Scholar] 
18. Saxena A. Congenital Heart Disease in India- A Status Report. Indian Pediatr. 2018 Dec 15;55(12)1075-1082. [Crossref][PubMed][Google Scholar]

19. Laya BF, Goske MJ, Morrison S, Reid JR, Swischuck L, Ey EH, et al. The accuracy of chest radiographs in the detection of congenital heart disease and in the diagnosis of specific congenital cardiac lesions. Pediatr Radiol. 2006 Jul;36(7)67781. doi: 10.1007/s00247-006-0133-2 [Crossref] [PubMed][Google Scholar]
20. Swenson, Jeanine $M$, et al. "Are chest radiographs and electrocardiograms still valuable in evaluating new pediatric patients with heart murmurs or chest pain?". Pediatrics. 99;1(1997)13;3. [Crossref][PubMed][Google Scholar]

21. Klewer SE, Samson RA, Donnerstein RL, Lax D, Zamora R, Goldberg SJ. Comparison of accuracy of diagnosis of congenital heart disease by history and physical examination versus echocardiography. Am J Cardiol. 2002 Jun 1;89(11)1329-31. doi: 10.1016/s0002-9149(02)02341-x [Crossref] [PubMed][Google Scholar] 